\title{
Comparison of sublingual versus vaginal routes of misoprostol in induction of labor
}

\author{
Madhu J.*, U. S. Hangaraga
}

Department of Obstetrics and Gynecology, Karnataka Institute of Medical Sciences, Hubli, Karnataka, India

Received: 06 May 2017

Accepted: 03 June 2017

\section{*Correspondence:}

Dr. Madhu J.,

E-mail: madhuobg@yahoo.co.in

Copyright: () the author(s), publisher and licensee Medip Academy. This is an open-access article distributed under the terms of the Creative Commons Attribution Non-Commercial License, which permits unrestricted non-commercial use, distribution, and reproduction in any medium, provided the original work is properly cited.

\begin{abstract}
Background: Induction of labor can be defined as an intervention intended to artificially initiate uterine contractions resulting in progressive effacement and dilatation of cervix. Present study was under taken to compare the efficacy of sublingual versus vaginal routes of administration of misoprostol for induction of labor.

Methods: Prospective observational study conducted from January 2010 to January 2011 in the Department of Obstetrics and Gynecology at Karnataka Institute of Medical Sciences, Hubli, Karnataka, India. The patients were selected from either antenatal ward or emergency admission to labor room. 100 women were selected for the study. 50 women in sublingual group and 50 in vaginal group. Main outcome measured were the number of doses of misoprostol administered, induction to delivery interval, incidence of cesarean sections, uterine hyperstimulation, meconium stained liquor and admission to NICU.

Results: Mean number of misoprostol doses required in sublingual group was significantly less compared to vaginal group ( $\mathrm{p}=0.0001)$. Mean induction to delivery time interval was significantly less in sublingual group $(\mathrm{p}=0.008)$. The incidence of cesarean sections, major side effects and vaginal delivery were similar in both the group. Neonatal outcomes of both groups were comparable.

Conclusions: Misoprostol was effective in induction of labor when administered by either sublingual or vaginal route. Sublingual route had significantly less induction to delivery time interval and less doses were required. Sublingual route seems to have better efficacy than vaginal route. Misoprostol seems to be acceptable to the patients and is an option to be considered to induce labor at term.
\end{abstract}

Keywords: Induction, Labor, Misoprostol, Sublingual, Vaginal

\section{INTRODUCTION}

Induction of labor can be defined as an intervention intended to artificially initiate uterine contractions resulting in progressive effacement and dilatation of cervix. There are various methods of induction of labor. The method of induction of labor chosen should achieve quick onset of labor, low incidence of failure to induce labor, should not cause an increase in perinatal morbidity and also prevent an increase in caesarean section or instrumental delivery rate as compared to spontaneous labor.

Misoprostol is a synthetic analogue of prostaglandin $E_{1}$ and is less expensive, more stable and easier to store than $\mathrm{PGE}_{2}$. It has been used 'off label' for preinduction cervical ripening and can be administered in various routes including sublingual, vaginal and oral. ${ }^{1}$ In year 2000 The American College of Obstetrics and Gynecologists' reaffirmed its recommendation for the use of this drug because of proven safety and efficacy. ${ }^{2,3}$ 
The vaginal absorption of misoprostol is inconsistent. This may be due to variation between women in the amount and $\mathrm{pH}$ of vaginal discharge. The misoprostol tablet is very soluble and can be dissolved in 20 when it is put under the tongue. In a pharmaco-kinetic study it has been observed that sublingual misoprostol has the shortest time to peak concentration, the highest peak concentration and the greatest bio availability when compared to other routes. This is due to rapid absorption through the sublingual mucosa as well as avoidance of first pass metabolism. ${ }^{4-6}$ The ideal dose, route and frequency of administration of misoprostol is still under investigation.

Only few studies have been reported in the literature of misoprostol given sublingually for labor induction. Hence this study was designed to compare the efficacy and safety of sublingual versus vaginal misoprostol for labor induction.

\section{METHODS}

This study was conducted in the Department of Obstetrics and Gynecology at Karnataka Institute of Medical Sciences, Hubli, Karnataka, India from January 2010 to January 2011. Over this period this study was carried out on pregnant women more than 37 weeks requiring induction of labor for any obstetrical and medical indication. The study was approved by ethical committee of the institute. The patients selected for the study were either from antenatal ward or emergency admission to labor room.

Pregnant women with singleton pregnancy with gestational age $>37$ completed weeks, vertex presentation, Bishop's score $\leq 5$ and good fetal cardiac activity were selected for the study.

Women with scarred uterus, malpresentations, G3 and above, fetal distress, those with contraindications for prostaglandins like asthma and glaucoma, placenta previa, CPD were excluded from the study.

A thorough history and clinical examinations was done. Demographic data such as age, parity, height, weight was recorded. Reason for induction and Bishop's score at the time of induction was recorded. Informed consent was taken from the patient for induction. Women were allotted for either of two groups by means of nonprobability convenience means of sampling. In women selected to receive sublingual misoprostol (Group A) 25 mcg of misoprostol was placed below the tongue and were instructed not to swallow the drug. Further doses were administered at 4 hours interval depending on the patients' response to a maximum of six doses. In women selected to receive vaginal misoprostol (Group B), 25 mcg of misoprostol was placed in posterior fornix. Further doses were administered at 4 hours interval depending on the patients' response to a maximum of six doses.
Once the patient went into active labor, partogram were maintained and fetal heart sounds were monitored strictly. Number of doses of misoprostol administered to each woman in both the groups was recorded. Induction to delivery interval time was recorded in all patients. Number of patients who required oxytocin augmentation in both the groups was recorded. Percentage of patients going for caesarean section in each group was calculated and the indication for the same was recorded.

Fetal outcome measures included APGAR scores at 1 minute and 5 minutes, passage of meconium and NICU admission. Number of babies with APGAR score of $<8$ at 1 minute and 5 minutes in either group was recorded. Number of babies that passed meconium in either group was recorded. Number of babies requiring NICU admission in each group was recorded.

\section{Statistical analysis}

For analysis of qualitative data, chi-square test was applied and for analysis of quantitative data, independent 't' test was applied.

\section{RESULTS}

Of hundred pregnant women recruited for the study, 50 women received sublingual misoprostol and 50 women received per vaginal misoprostol.

A comparative study containing 100 pregnant women (>37 weeks) undergoing induction of labor;

- 50 patients in group A (Sublingual misoprostol)

- 50 patients in group B (per vaginal misoprostol)

Table 1: Parity distribution.

\begin{tabular}{|lll|}
\hline Parity & Group A $(\mathbf{n}=\mathbf{5 0})$ & Group B $(\mathbf{n}=50)$ \\
\hline Primi & 35 & 36 \\
\hline Gravida 2 & 15 & 14 \\
\hline
\end{tabular}

Table 2: Age distribution.

\begin{tabular}{lll} 
& Group A & Group B \\
Mean age in years & $22.06 \pm 2.469$ & $22.80 \pm 3.320$ \\
\hline
\end{tabular}

Distribution in age and parity were comparable between two groups (Table 1 and 2) Distribution in age was comparable between two groups with mean age of women in Group A being 22.43 years and that in Group B was 22.24 years. $70 \%$ of women in Group A and $72 \%$ of women in Group B were primigravida

The various indications for induction of labor in women of both groups were comparable (Table 3). Pre-induction Bishop score was comparable between two groups (Table 4). 
Table 3: Indication for induction of labor.

\begin{tabular}{|lll|}
\hline Indications & Group A & Group B \\
\hline Postdated pregnancy & 17 & 18 \\
\hline PROM & 14 & 11 \\
\hline $\begin{array}{l}\text { Pre eclampsia/gestational } \\
\text { hypertension }\end{array}$ & 13 & 17 \\
\hline Eclampsia & 4 & 3 \\
\hline IUGR & 2 & 1 \\
\hline
\end{tabular}

Table 4: Pre-induction bishop score.

\begin{tabular}{|lll|}
\hline Bishop's score & Group A & Group B \\
\hline $1-2$ & 19 & 18 \\
\hline $3-4$ & 30 & 31 \\
\hline $5-6$ & 1 & 1 \\
\hline
\end{tabular}

Number of doses of misoprostol required was less in sublingual group when compared to per vaginal group and this was statistically significant $(\mathrm{p}=0.003)$ (Table 5).

Table 5: Number of doses of misoprostol administered.

\begin{tabular}{|llc|}
\hline $\begin{array}{l}\text { Number of doses } \\
\text { of misoprostol }\end{array}$ & Group A & Group B \\
\hline $1-2$ & 40 & 24 \\
\hline $3-4$ & 8 & 18 \\
\hline $5-6$ & 2 & 8 \\
\hline & $\begin{array}{l}\text { Group A required less number of } \\
\text { doses compared to Group B chi- } \\
\text { Inference }\end{array}$ & square=11.446, df=2 p=0.003 \\
\hline
\end{tabular}

The mean number of doses required in group A patients was $1.86 \pm 1.088$ and that in group B was $2.96 \pm 1.442$ and this was statistically significant (by applying independent $\mathrm{t}$ test, $\mathrm{t}=-4.305, \mathrm{df}=98, \mathrm{p}=0.0001)$.

Table 6: Induction to delivery time interval.

\begin{tabular}{|lll|}
\hline Time interval & Group A & Group B \\
\hline$<12$ hours & 29 & 19 \\
\hline$>24$ hours & 15 & 24 \\
\hline & $\begin{array}{l}\text { Induction delivery } \\
\text { interval was less in }\end{array}$ \\
\hline $\begin{array}{l}\text { Inference } \\
\text { Group A compared to } \\
\end{array}$ & 3 \\
& $\begin{array}{l}\text { Group B. X2=4.15, } \\
\mathrm{df}=1, \mathrm{p}<0.05\end{array}$ \\
\hline
\end{tabular}

Induction to delivery time interval in Group A was less compared to Group B and was statistically significant. Mean induction to delivery time in group A was 11 hours 37 minutes \pm 5 hours 56 minutes and that in Group B it was 15 hours 14 minutes \pm 6 hours 34 minutes. This is statistically significant with $\mathrm{t}=-2.709, \mathrm{df}=86$ and $\mathrm{p}=0.008$ (Table 6).

The number of patients who required oxytocin augmentation was less in Group A (32\%) than in Group
B $(40 \%)$ but was not statistically significant. $\left(x^{2}=3.3\right.$, $\mathrm{p}=0.06)$ (Table 7).

Table 7: Oxytocin requirement.

\begin{tabular}{|lll|}
\begin{tabular}{|lll} 
Oxytocin infusion \\
requirement
\end{tabular} & Group A & Group B \\
\hline Yes & 16 & 20 \\
\hline No & 34 & 30 \\
\hline
\end{tabular}

Outcome of induction of labor was comparable in both groups. Six patients in Group A underwent LSCS (Indications - fetal distress - 3, failure to progress - 2 and cord prolapse - 1) while seven patients in Group B underwent LSCS (indications - failed induction 3, foetal distress 4). This was not statistically significant (Table 8).

Table 8: Outcome of induction.

\begin{tabular}{|lll|}
\hline Outcome & Group A & Group B \\
\hline Normal vaginal delivery & $40(80 \%)$ & $40(80 \%)$ \\
\hline Caesarean section & $6(12 \%)$ & $7(14 \%)$ \\
\hline Outlet forceps & $4(8 \%)$ & $3(6 \%)$ \\
\hline
\end{tabular}

Four patients in Group A and three patients in Group B underwent instrumental vaginal delivery (outlet forceps). Outlet forceps delivery was done for fetal distress in two patients of Group A and two patients of Group B. Outlet forceps was applied for failed maternal forces for 2 patients in group A and one patient in Group B.

Table 9: Neonatal outcome.

\begin{tabular}{|lll|ll|}
\hline Outcome & \multicolumn{2}{c}{ Group A } & Group B \\
\hline APGAR score $<8$ & 1 min & 5 min & 1 min & 5 min \\
\hline & 7 & 4 & 6 & 4 \\
\hline Meconium & 10 & & 10 & \\
\hline NICU admission & 4 & & 4 \\
\hline
\end{tabular}

Maternal side effects such as nausea, vomiting, diarrhea was observed only in few patients of both groups (Group $\mathrm{A}=4$, Group $\mathrm{B}=4$ ). In Group $\mathrm{A}$ one patient had tachysystole (Table 9). No major maternal side effects were noted in either of two groups. Fetal distress was noticed in five patients in group A, out of which three patients were taken for caesarean section as it occurred in first stage of labor and two patients underwent forceps delivery due to fetal distress in second stage of labor. In Group B, fetal distress was noticed in four patients in first stage who underwent caesarean section and two patients underwent forceps delivery because of fetal distress in second stage of labor

7 neonates at 1 minute \& 4 at 5 minutes in Group A and 6 babies at 1 minute and 4 at 5 minutes in Group B had an APGAR score of $<8$ and this was not statistically significant. Equal number of neonates (10) in both groups had passed meconium and 4 babies in both groups were admitted to neonatal intensive care (Table 9). 


\section{DISCUSSION}

The present study compares the efficacy of sublingual versus per vaginal route of Misoprostol administration in pregnant females at term in terms of successful vaginal delivery, induction delivery time interval, number of doses of Misoprostol required, need for oxytocin augmentation and fetal outcome measures such as APGAR score at birth, passage of meconium and admission to NICU. There have not been much previous studies on sublingual Misoprostol used for induction of labor.

In current study, the rate of LSCS in sublingual group was $12 \%$ and in per vaginal group it was $14 \%$. Hofmey MG compared sublingual v/s oral misoprostol and found fewer incidence of caesarean sections in sublingual group as compared to oral group. ${ }^{7}$ Louis Sanchez Ramos reported vaginal delivery rate of $90.7 \%$ with $50 \mathrm{mcg}$ of vaginal misoprostol. ${ }^{8}$

Gupta HP et al compared $25 \mathrm{mcg}$ of vaginal misoprostol with $50 \mathrm{mcg}$ of misoprostol in induction of labor at term and found $18 \%$ of caesarean section with $25 \mathrm{mcg}$ of misoprostol and $15 \%$ of caesarean section with $50 \mathrm{mcg}$ misoprostol. ${ }^{9}$ The findings of present study are comparable to the previous studies.

In present study, mean induction delivery time interval with sublingual route was $11.37 \pm 5.56$ hours and that in Group B was 15.14 hours \pm 6.34 hours. Wing et al showed in his study of induction of labor with $25 \mathrm{mcg}$ of Misoprostol mean induction delivery interval of $22.1 \pm 14.5$ hours. ${ }^{10}$ Buggalo et al in his study of induction of labour with $50 \mathrm{mcg}$ of Misoprostol found mean induction delivery time interval of 10.4 hours. ${ }^{11}$ The mean induction delivery time interval of present study is comparable with that of previous studies.

In the present study, $58 \%$ of patients in sublingual group and $38 \%$ of patients in per vaginal group delivered within 12 hours. $84 \%$ of patients in sublingual group and $80 \%$ of patients in pervaginal group delivered within $24 \mathrm{hrs}$. Shetty et al in the study of sublingual Misoprostol for induction of labor at term showed $73.8 \%$ of patients delivered within 24 hours $^{12}$.Wing et al 1995 reported 30\% vaginal deliveries within $12 \mathrm{hrs}$ with $25 \mathrm{mcg}$ of misoprostol. ${ }^{10}$

In the present study, 3 women underwent caesarean section for failed induction in vaginal group whereas none of the women in sublingual group had failed induction.

In the present study requirement of Oxytocin augmentation was $30 \%$ with sublingual Misoprostol and $40 \%$ with per vaginal Misoprostol. Reported incidence of Oxytocin augmentation of labor in cases induced by Misoprostol range from $29.4 \%$ to $32.1 \%$. In the present study, the need for Oxytocin augmentation of labor was more in per vaginal group.

The neonatal outcome between the two groups was similar in the present study. Shetty et al in 2002 compared oral v/s sublingual misoprostol for induction of labor and found no significant difference in neonatal outcome between the two groups. ${ }^{12}$ Neonatal side effects such as passage of meconium was seen in $20 \%$ of babies in both groups, however admission to NICU was only $8 \%$ in both groups. Wing et al in 1995 reported $17.4 \%$ meconium stained liquor in his study with $25 \mathrm{mcg}$ of Misoprostol for induction of labor. ${ }^{13}$

In the present study, the incidence of side effects such as nausea, vomiting, diarrhoea were minimal in both the groups (Gr A - 4, Gr B - 4). One patient in sublingual group had tachysystole. The incidence of side effects in our study was similar to previous studies.

\section{CONCLUSION}

Misoprostol is effective in induction of labor both with sublingual and vaginal routes. Sublingual route has significantly less induction time delivery interval. Number of doses required in sublingual group was lesser compared to pervaginal group. Only few patients had minor side effects in both groups. No major side effects were reported. Administration by sublingual group avoids repeated vaginal examination. Sublingual route seems to have better efficacy than vaginal Misoprostol, seems to be acceptable to patients and is an option to be considered to induce labour at term.

\section{Funding: No funding sources Conflict of interest: None declared}

Ethical approval: The study was approved by the Institutional Ethics Committee

\section{REFERENCES}

1. Off label drug use and FDA review of supplemental drug applications hearing before the subcommittee on human resources and inter governmental relations of the committee on government reform and oversight, house of representatives, $104^{\text {th }}$ congress, $2^{\text {nd }}$ session. Washington: U.S G.P.O 1996;53-94.

2. American College of Obsetrics and Gynaecologists committee on Gynecological practices. Induction of labour with misoprostol. 1999;228

3. American college of Obstetrics and Gynaecologists committee on Gynaecological practice. Response to Searle's drug warning on misoprostol. 2000;248.

4. Zeiman M, Fong SK, Nowitz NL, Bunskter D, Darney PD. Absorption kinetics of misoprostol with oral or vagina; administration. Obstet Gynecol. 1997;90:80-82.

5. Tang OS, Scheewer H, Seyberth HW, Lee SWH, Ho PC. Pharmacokinetics of different routes of misoprostol. Human Reprod. 2002;17:332-6. 
6. Tang OS, Gemzell-Danielson K, Ho PC. Review article. Misoprostol: pharmacokinetic profiles, effects on uterus and side effects. Int $\mathrm{J}$ Obstet Gynecol. 2007;99:S160-S167.

7. Muzzoni C, Hofemeyer GJ. Buccal or sublingual misoprostol for cervical ripening and induction of labour. Cochrane Database Syst Rev. 2004;18(4):CD 004221 .

8. Sanchez-Ramos L, Chen AH, Kaunitz AM, Gaudier FL, Delke I. Labor induction with intravaginal misoprostol in term premature rupture of membranes: a randomized study. Obstet Gynecol. 1997;89(6):909-12.

9. Guptha HP, Singh U, Mehothra S. Comparative evaluation of $25 \mu \mathrm{gm}$ and $50 \mu \mathrm{gm}$ of vaginal misoprostol for induction of labour. J Obstet Gynecol India. 2010;60:51-54.

10. Wing DA, Rahall A, Jones MM, Goodwin TM, Paul RH. Misoprostol, an effective agent for cervical ripening and labour induction. American J Obstet Gynecol. 1995;172:1811-6

11. Bughalo A, Bique C, Machungo F, Faundes A. Low dose vaginal misoprostol for induction of labour with a live foetus. Int J Obstet Gynecol. 1995;49:149-55.

12. Shetty A, Danielian P, Templeton A. Sublingual misoprostol for the induction of labor at term. Am J Obstet Gynecol. 2002;186(1):72-6.

13. Wing DA, Rahall A, Jones M, Goodwin TM, Paul RH. Misoprostol an effective agent in cervical ripening and labor induction. Am J Obstet Gynecol. 1995; 172:1804-10.

Cite this article as: Madhu J, Hangaraga US.

Comparison of sublingual versus vaginal routes of misoprostol in induction of labor. Int $\mathbf{J}$ Reprod Contracept Obstet Gynecol 2017;6:3062-6. 